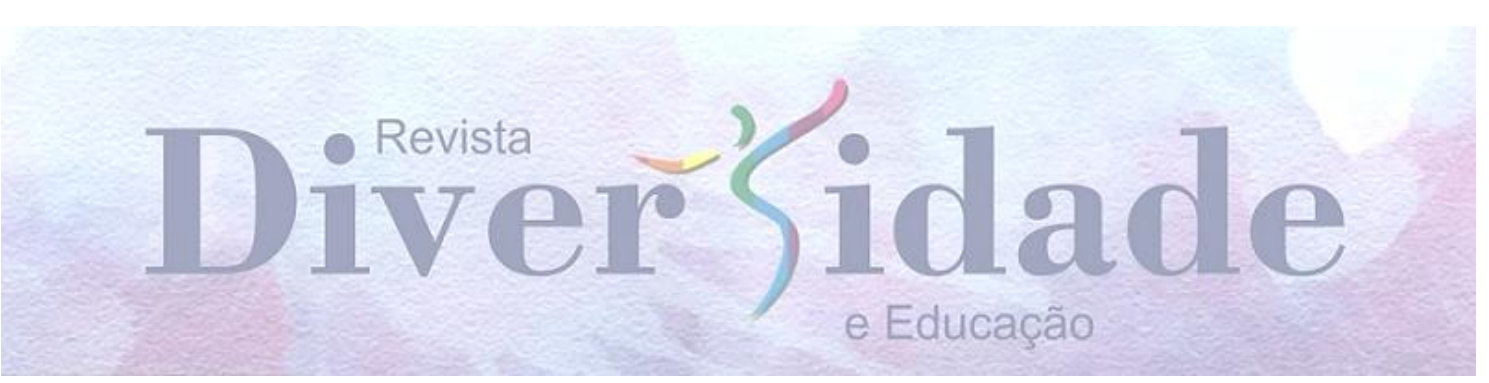

\title{
AS QUESTÕES DE GÊNERO E SEXUALIDADE E O MOVIMENTO ESCOLA SEM PARTIDO: QUAL O IMPACTO PARA A BASE NACIONAL COMUM CURRICULAR?
}

\section{QUESTIONES DE GÉNERO Y SEXUALIDAD Y EL MOVIMIENTO ESCUELA SIN PARTIDO: ¿CUÁL ES EL IMPACTO EN LA BASE CURRICULAR ESTUDIOS NACIONAL COMÚN?}

\section{THE ISSUES OF GENDER AND SEXUALITY AND THE UNPOLITICAL SCHOOL: WHAT IS THE IMPACT FOR THE NATIONAL COMMON CURRICULAR BASE?}

\author{
Marina Silveira Bonacazata Santos ${ }^{1}$ \\ Maria Carolina Miesse ${ }^{2}$ \\ Fabiana Aparecida de Carvalho ${ }^{3}$
}

\section{RESUMO}

Analisam-se questões relacionadas ao gênero e à sexualidade frente ao Movimento Escola sem Partido (MESP) e impactos na Base Nacional Comum Curricular (BNCC). A pesquisa foi de cunho qualitativo, teórico-bibliográfico e documental. Primeiramente, critica-se historicamente o surgimento do MESP, com destaque para as ideologias nas quais se ancora. Em um segundo momento, as correlações do MESP com as questões de gênero e sexualidade são descritas, dando maior ênfase aos motivos políticos, econômicos e morais defendido por apoiadoras/es do movimento nas disputas por interferências nas escolas. Finalmente, relacionam-se os efeitos do MESP com a

\footnotetext{
1 Mestranda no Programa de Pós-Graduação em Educação para a Ciência e a Matemática (PCM), Universidade Estadual de Maringá (UEM). Graduada em Ciências Biológicas (Bacharelado e Licenciatura), pela Universidade Estadual de Maringá (UEM), Bolsista CAPES. E-mail: marina_bonacazata@hotmail.com

${ }^{2}$ Mestranda em Educação no Programa de Pós-Graduação em Educação (PPE), Universidade Estadual de Maringá (UEM), Bolsista da CAPES. E-mail: Mariamiesse@ hotmail.com

3 Doutora em Educação para a Ciência e a Matemática, Universidade Estadual de Maringá (UEM), Professora Adjunta do Departamento de Biologia, Universidade Estadual de Maringá (DBI/UEM), Coordenadora do Grupo de Estudos das Pedagogias do Corpo e da Sexualidade (GEPECOS/UEM). Email: facarvalho@uem.br
} 
conjuntura de produção da BNCC, destacando a supressão e o apagamento dos termos gênero, sexualidade e diversidade sexual dos currículos escolares do ensino de Ciências e Biologia.

PALAVRAS-CHAVE: Educação Básica. Docência. Ensino de Ciências e Biologia.

\title{
RESUMEN
}

Se analizan temas relacionados con género y sexualidad en relación con el Movimiento Escuela Sin Partido (MESP) y los impactos en la Base Curricular Común Nacional (BNCC). La investigación fue cualitativa, teórico-bibliográfica y documental. En primer lugar, se critica históricamente el surgimiento del MESP, haciendo hincapié en las ideologías en las que está anclado. En un segundo paso, se describen las correlaciones del MESP con los temas de género y sexualidad, dando mayor énfasis a las razones políticas, económicas y morales que defienden los partidarios del movimiento en las disputas por la injerencia escolar. Finalmente, los efectos del MESP se relacionan con la situación de producción del BNCC, destacando la supresión y borrado de los términos género, sexualidad y diversidad sexual en los currículos escolares de enseñanza de Ciencias y Biología.

PALABRAS-CLAVE: Educación básica. Enseñando. Docencia de Ciencias y Biología.

\begin{abstract}
Issues related to gender and sexuality are analyzed in relation to the Unpolitical School (MESP) and impacts on the National Common Curricular Base (BNCC). The research was qualitative, theoretical-bibliographic and documentary. First of all, the emergence of the MESP is historically criticized, with emphasis on the ideologies in which it is anchored. In a second step, MESP's correlations with gender and sexuality issues are described, giving greater emphasis to the political, economic and moral reasons defended by supporters of the movement in disputes over school interference. Finally, the effects of MESP are related to the production situation of the BNCC, highlighting the suppression and erasure of the terms gender, sexuality and sexual diversity in the school curriculum of Science and Biological Studies
\end{abstract}

KEYWORDS: Basic Educacion. Teaching. Science and Biological Studies.

$$
* * *
$$

\section{Introdução}

Com a Lei $\mathrm{N}^{\circ}$ 13.415/2017 (BRASIL, 2017), que deflagrou a reforma da educação básica a partir do Ensino Médio, ainda na gestão do Presidente Michel Temer (2016-2019), a Lei No 9.394/1996 (LDB/96) (BRASIL, 1996) englobou efetivamente a ideia de um currículo comum e padronizado para todas as escolas do país no formato de uma Base Nacional Comum Curricular (BNCC).

A BNCC visa ser um instrumento de orientação dos currículos educacionais ao definir o conjunto de competências cognitivas, competências sócio emocionais e habilidades básicas a serem adquiridas pelas/os estudantes ao longo da educação básica, 
instrumentalizando as/os escolares para a aquisição dos conhecimentos essenciais à vida em sociedade e para suas inserções no mercado de trabalho. Com esse direcionamento e com a consolidação da BNCC do Ensino Fundamental e do Ensino Médio no Governo Jair Bolsonaro (2019-2023), os currículos passaram a se organizar em perfis formativos e a congregar as cinco áreas de conhecimento e suas tecnologias associadas: linguagens, matemática, ciências da natureza, ciências humanas e formação técnica e profissional.

Conforme aponta Myriam Krasilchik (2000), a cada governo um novo contexto reformista atinge principalmente os ensinos fundamental e médio, deflagrando interferências centralizadoras do Estado na emissão de normas e regulamentos e a abertura a interesses econômicos, políticos, corporativos que afetam as escolas e o acesso à educação. No bojo da reforma educacional, consubstanciada na BNCC, temos presenciado a disputa de empresários e grupos privados no direcionamento da formação das/os jovens em fase de escolarização, ou seja, nos últimos anos, a organização do currículo tem sido palco de disputas de setores neoliberais cujo intento é a interferência para a dissolução da escola e da educação pública de qualidade no Brasil (BELLINI, 2020; CARVALHO, 2020).

As discussões inauguradas entorno da BNCC endurecem o caráter educacional da escola, permitindo o aumento da interferência das corporações privadas que passam, com certo estatuto de legalidade, a dizer o que é e não currículo, o que deve ou não ser ensinado, o que pode ser discutido, as prioridades na formação, o que é educação, o que é sociedade, entre outras questões. Sob esse prisma, a BNCC torna-se um caminho para a desigualdade educacional, posicionando o currículo como um trampolim para a formação de mão de obra a suprir as demandas do mercado de trabalho. Parte desse contexto pode ser exemplificado com a não obrigatoriedade das disciplinas de sociologia, filosofia e artes, e também com a implantação de percursos que facultam ou minimizam os debates de temas sociais e científicos considerados controversos, polêmicos e que requerem, sobretudo, condições problematizadoras para $\mathrm{o}$ desenvolvimento da autonomia, do pensamento crítico e da emancipação das pessoas.

Neste cenário, é instituída uma atmosfera de perseguição e cerceamento à atuação docente, de censura ao conhecimento científico e de imposição de pseudoverdades com a distorção dos conteúdos, dos fatos históricos e das circunstâncias 
escolares. Trata-se, portanto, da instauração de uma espécie de "biopolítica"4 (FOUCAULT, 2008) a regular a vida escolar, os corpos das/os estudantes e o que pode ser pensado no corpus teórico das instituições de ensino.

Tal perseguição, conforme enfatiza a Professora Marta Bellini (2020), é decalque das políticas educacionais estadunidenses, das corporações e governos submetidos ao Banco Mundial, ao Fundo Monetário Internacional e às Igrejas, com o intuito de censura, discriminação e sabotagem das escolas públicas, a forte redução de recursos, com o esvaziamentos dos fundos públicos e a financeirização de sistemas particulares de ensino, com a redução das políticas educacionais e o sequestro do pensamento pela lógica empresarial ou pelo negacionismo da ciência e supervalorização dos dogmas religiosos. Assim, estratégias de censura são direcionadas "aos grupos de pesquisa com temas críticos, temas das sexualidades, das ciências sociais, da filosofia", da ciência "e [...] como estratégias de extermínio da educação" (BELLINI, 2020, p. 09).

A autora prossegue afirmando que, ao longo das 3 últimas décadas, nos Estados Unidos as chamadas crises escolares foram resolvidas com projetos e documentos educacionais segregadores de pobres, negras/os, indígenas e trabalhadoras/es; aponta também que a resposta do governo norte americano foi responsabilizar diretoras/es e professoras/es pelas desigualdades estruturais no sistema educacional. Essa foi uma discursividade sustentada por empresários da educação proponentes da padronização curricular e das reformas educacionais para esse país, seguida de estratégias difusas com vieses morais a para criminalizar as/os educadoras/es e pautá-las/os como "bodes expiratórios da suposta crise educacional” (BELLINI, 2020, p. 21).

Tais apontamentos evidenciam o currículo como um espaço construtor de funções sociais, educativas, formais, da vivência cotidiana prática (SACRISTÁN, 2002), mas também um espaço de poder, de disputas, de representações e discursividades cujo efeito maior é a produção das identidades e identificações das/os sujeitos escolares (SILVA, 2007).

Dessa feita, embora no Brasil a ideia de uma Base Comum Curricular já estivesse prevista desde a Constituição Federal de 1988 e na LDB/1996, sendo a pauta curricular atinente ao Ministério da Educação (MEC) e ao Conselho Nacional de Educação, diversos setores privatizantes se vincularam ao Estado conseguindo, em momentos de conflitos sociais e convulsões políticas, que se estabeleceram desde

${ }^{4} \mathrm{O}$ conceito de biopolítica compreende um estilo de governo por intermédio da transformação da vida em produção e do controle do corpo individual e populacional por táticas do Estado.

Revista Diversidade e Educação, v. 9, n. Especial, p. 509-531, 2021. $\quad$ Doi: 10.14295/de.v9iEspecial.12588 E-ISSN: 23588853 
2013/2014, interpor um caráter conservador nas discussões das versões da Base. Este volta-se ao empreendedorismo para o mercado, com diversas restrições à autonomia das/os educadoras/es e estudantes quando se evidenciam, principalmente, os apagamentos das discussões sobre direitos humanos e civis, diversidade cultural, inclusão social, sobre gênero e sexualidade nas competências específicas para o Ensino Fundamental e Médio e nos encaminhamentos teórico-metodológicos previstos.

Um dos grupos privados mais atentos à votação dos Planos de Educação e à imposição da filosofia neoliberal da BNCC é o Movimento Escola sem Partido (MESP).

O MESP carrega consigo ideários conservadores e recebe apoio de diversas bancadas religiosas e de extrema direita que se colocam contrárias à discussão de gênero e sexualidade nas escolas. As/os apoiadoras/es desse movimento defendem a existência do que chamam de "ideologia de gênero", ou seja, um propósito disseminado em escolas e universidades cujo objetivo é afrontar os valores morais e cristãos subvertendo os corpos numa espécie de "ditadura gay e feminista", conforme a visão das/os adeptos do MESP e de grupos como "Cristãos contra a Ideologia de Gênero", "Família na escola", "Movimento Brasil Livre", que ocuparam as casas legislativas, o executivo e fatias do poder judiciário no Brasil, tentando impedir o acesso dos grupos minoritários à vida pública" (CARVALHO; POLIZEL; MAIO, 2016, p. 198).

Procurando traçar uma genealogia da perseguição à educação para o gênero e para a sexualidade empreendida pelo MESP, com base na leitura de projetos de lei (PL), das postagens extraídas do site movimento e do cotejamento teórico com autoras/es que se dedicam ao tema, o presente artigo (recorte de pesquisa sobre o tema) visa debater a supressão das discussões e conteúdos de gênero ${ }^{5}$ e sexualidade da BNCC no itinerário formativo "Ciências da Natureza e suas tecnologias". Essa negligência dos termos e ações que contribuem para posturas de respeito à diversidade humana poderá impactar diretamente os currículos de Ciências e Biologia nas escolas, sustentando ideais preconceituosos no imaginário das pessoas sujeitos da educação e contribuindo para a manutenção das desigualdades, dos sexismos, dos racismos e das violências de gênero e LGBTfóbicas em nossa sociedade. Apresentamos nossas colocações nas seções que se

5 Tomamos o gênero por sua perspectiva de análise e discussões das condições sociais que atravessam a vida das pessoas, das diferenças, das igualdades, equidades, das violências, das intersecções com outras categorias, entre elas, classe, etnia, cor e pertencimento cultural. Não nos alinhamos aos binarismos e determinismos biológicos que pautam as relações de gênero apenas pelo aspecto da cisgeneridade e do heteropatriarcado. Consideramos também o gênero como um território de disputa, produção de saberes e de emancipações. 
seguem destacando: a) o surgimento do MESP e sua filiação ao conservadorismo; b) a consubstanciação dos pressupostos da suposta "ideologia de gênero" e seus perigos; c) o impacto dessas posições na consolidação da BNCC e da reforma educacional brasileira.

\section{O surgimento do MESP no bojo do conservadorismo}

O MESP inaugurou-se no Brasil, ainda que inexpressivamente, em 2004 com uma "dupla certidão de nascimento" (PENNA; SALLES, 2017): 1) com as ações impetradas pelo advogado Miguel Nagib contra escolas paulistas acusadas de doutrinação ideológica; 2) com a retórica reacionária de formadores de opinião, influenciadores digitais, teóricos da conspiração e defensores religiosos, entre os quais, o jornalista e astrólogo Olavo de Carvalho, com forte poder de persuasão e geração de pânico moral na população (JUNQUEIRA, 2017; FURLAN; CARVALHO, 2020) ao mobilizar uma concepção político-ideológica contrária ao pensamento crítico, às posições esquerdo-partidárias, aos alinhamentos teóricos socialistas, comunistas e feministas. Nagib não concebeu um movimento originalmente brasileiro, mas incorporou proposições de organizações norte-americanas, notadamente atuantes nas décadas de 1980 e 1990, com o intuito de levar a interferência privada e o controle dos conteúdos curriculares às escolas e universidades; dessas podemos citar: a "No Indocrination" - responsável por fiscalizar a doutrinação nas escolas; a organização "Campus Watch" - fiscalizadora das universidades; e o grupo cristão "Creation Studies Institute" - defensores da Bíblia e do criacionismo (ESPINOSA; QUEIROZ, 2017; CARVALHO, 2020; CARVALHO; POLIZEL; MAIO, 2016).

No ano de 2004, o MESP não teve reconhecimento por falta de apoio político. Todavia, ganhou volume com a fomentação do discurso conservador contrário à visibilidade dos direitos humanos e incentivador da política do Estado mínimo, ou seja, da diminuição da interferência dos Governos nas políticas públicas para a igualdade e a equidade social e na ordem econômica da nação.

A partir desse alinhamento, a retórica conservadora do MESP foi paulatinamente avançando no bojo das manifestações populares de 2013, a exemplo, a movimentação pelo "Passe Livre", o "Vem para a Rua", o "Não vai ter copa" que culminaram em discursividades contrárias ao Governo Dilma Rousseff (2011-2016) e ao Partido dos Trabalhadores (PT) (CARVALHO; POLIZEL; MAIO, 2016). Esse descontentamento manifesto nas ruas foi, segundo estudiosas/os (RUBIM; ARGOLO, 2018; BIROLI, 2018), um embrião dos discursos de ódio às posições esquerdo-partidárias no país, 
gestado também em ações misóginas e sexistas, e um dos responsáveis por consolidar o afastamento da Presidenta Dilma, em 2016, via estratagema político de um golpe parlamentar.

No ano de 2014, o movimento ganhou o apoio político das bancadas legislativas do agronegócio, da defesa de armas e das igrejas conhecidas como "bancadas boi-balabíblia" (CARVALHO; POLIZEL; MAIO, 2016), consolidadas por lideranças desses setores, coligadas a distintos partidos políticos de direita e extrema-direita que também recebem a influência da cartilha conspiracionista de Olavo de Carvalho. Tais bancadas foram fundamentais para o desagendamento das ações educativas e metas voltadas à promoção da igualdade e equidade dos gêneros, à erradicação das violências sexistas e LGBTfóbicas, à educação para a sexualidade e ao respeito quanto à diversidade durante a votação dos Planos de Educação.

Esse alinhamento foi fundamental para influenciar escolas e famílias com a ideia do pensamento apartidário nas questões curriculares e nas atuações docentes. No mesmo ano e em 2015, a família Bolsonaro se alinha à Miguel Nagib com a proposição de projetos de lei na Câmara Municipal e na Assembleia Estadual Legislativa do Rio de Janeiro. Tais projetos (PL). Estes foram posteriormente transformados em minutas de Lei disponibilizadas na internet para "que políticas/os dos Estados e Municípios e pessoas interessadas possam copiar e garantir a representatividade do movimento em casas legislativas, em seus núcleos escolares e familiares" (FURLAN; CARVALHO, 2020, p. 172).

O MESP se estabeleceu, portanto, com o apoio conjunto de estudantes, familiares, políticas/os e empresárias/os empenhadas/os em modificar estruturalmente o direito à educação e de regularizar a liberdade de expressão, a liberdade de cátedra e a prática docente ao impor regras para a livre expressão do pensamento e dos currículos nas escolas brasileiras. Esses sujeitos motivaram-se por três objetivos: "a descontaminação e desmonopolização política e ideológica das escolas; o respeito à integridade intelectual e moral dos estudantes; e o respeito ao direito os pais de dar aos seus filhos uma educação moral que esteja de acordo com suas convicções" (CARA, 2016, p. 4).

De acordo com o site oficial do MESP (ESCOLA.... 2021), faz-se necessário "descontaminar" a escola de posições político-ideológicas cujos pretextos seriam transmitir uma visão crítica da realidade através da doutrinação das/os alunas/os. Dentre 
os dispositivos criados para a imposição dessa descontaminação, o MESP endossa a adoção de um cartaz com direitos e deveres das professoras/es nas salas de aula, o qual deverá ser fixado em cada sala de aula das escolas brasileiras (Figura 1).

Figura 1: Cartaz difundido pelo MESP com os deveres do professor

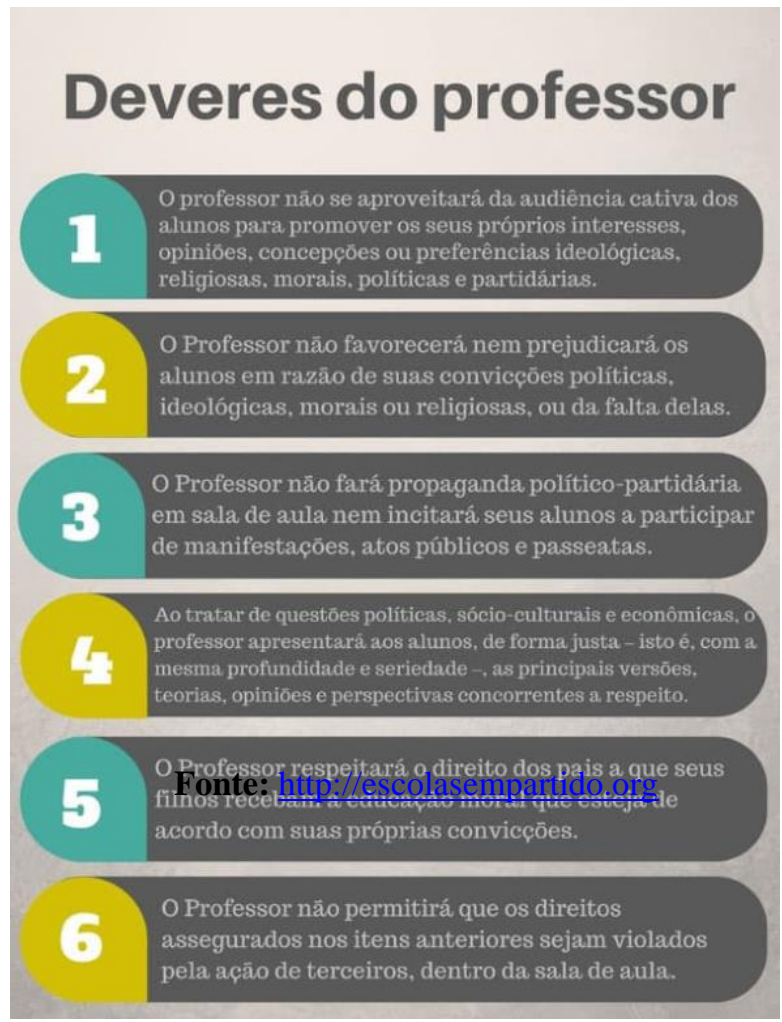

O cartaz evidencia o posicionamento conservador do movimento numa pedagogia da negação da atuação escolar. Aponta que as/os docentes não podem deixar transparecer em suas aulas: as suas convicções morais, políticas, religiosas ou partidárias, não sendo permitido, inclusive, incentivar a participação das/os escolares em manifestações sociais e políticas, em grêmios estudantis, em assembleias do movimento estudantil e tampouco incentivar o debate de temas controversos e políticos em sala de aula.

Segundo o MESP, os docentes têm o dever de respeitar o direito de mães, pais e familiares na educação das/os filhas/os, enfatizando que a educação escolar deva estar em consonância com a educação moral e religiosa e com os princípios das famílias. Nota-se o aumento da interferência de uma entidade privada, a família, no foro social e coletivo da escola, limitando a liberdade de cátedra nas aulas e limitando professoras/es 
na discussão de conteúdos que envolvam posicionamentos políticos, críticas aos dogmas religiosos e conteúdos acerca da diversidade cultural e sexual nas escolas. As/os docentes passam, já apontado nas considerações de Marta Bellini (2020), a serem os alvos principais do movimento e vítimas de vigilância inclusive das/os próprias/os estudantes.

De 2014 aos dias atuais, o MESP protocolou mais de 150 PL's em todo o país, incluindo dispositivos que visam a interferir na LDB/1996, combater a doutrinação ideológica e proibir as discussões de gênero nas escolas. Desses PL's, destacamos: o PL $\mathrm{N}^{\circ} 867 / 2015$, de autoria do deputado cristão Izalci Lucas, apensado a projetos mais antigos em tramitação na Câmara das/os deputadas/os, cuja finalidade é incluir entre as diretrizes e bases da educação nacional o Programa Escola sem Partido (BRASIL, 2015a); e o PL No 246/2019, de autoria da empresária e deputada Bia Kicis, que permite a gravação das aulas e o monitoramento dos conteúdos escolares por parte de estudantes e familiares (BRASIL, 2019). A perversidade de tais PL's reside na exposição das/os docentes numa verdadeira "caça às bruxas" (CARVALHO; POLIZEL; MAIO, 2016), que torna a escola vulnerável a diversas estratégias de exposição nas redes sociais e a uma "pedagogia do medo" (CARVALHO, 2020) monitorada por dogmas e convicções morais e religiosas.

Conforme destacado no Art. $9^{\circ}$ do PL No 246/2019, o MESP estaria aplicado:

I - às políticas e planos educacionais; II - aos conteúdos curriculares; III aos projetos pedagógicos das escolas; IV - aos materiais didáticos e paradidáticos; V - às avaliações para o ingresso no ensino superior; VI - às provas de concurso para ingresso na carreira docente (BRASIL, 2019, p. 2).

Além dessa inserção em regimentos educacionais, materiais didáticos, projetos escolares e em instituições de ensino, em seu Art. 2 dispõe que "o Poder Público não se imiscuirá no processo de amadurecimento sexual dos alunos nem permitirá qualquer forma de dogmatismo ou proselitismo na abordagem das questões de gênero" (BRASIL, 2019, s/p). "Por esses e outros intentos, o projeto de Bia Kicis torna-se o mais persecutório em termos da instalação do poder de vigilância sobre a autonomia escolar e da junção gênero-comunismo" (FURLAN; CARVALHO, 2020, p. 178).

O MESP, portanto, congrega ideias conservadoras que interferem de modo direto na educação e nos currículos. Como afirma Miguel (2016), é perceptível a presença de enunciados em que a desigualdade é exaltada com discursos reacionários 
conjugados à uma visão ao fundamentalismo religioso e à recuperação da discursividade anticomunista - uma estratégia da direita e do neoliberalismo para atacar a

educação sexual como um conspiração comunista para destruir a família e enfraquecer as vontades nacionais, debilitar os tabus religiosos, promover a aceitação de relações sexuais anormais, distorcer os padrões normais e destruir a coesão sexo-gênero, rebaixando as pessoas (especialmente brancas) a delírios sexuais como homossexualidade, pornografia, aborto, sexo e relacionamentos extraconjugais. Essa discursividade vem sendo recuperada e legitimada dentro de uma pseudopolítica que coliga apelos econômicos aos discursos dogmáticos de defesa moral da honra, da tradição familiar e da nação brasileira, enfraquecendo as conquistas e avanços progressistas para a consolidação de uma educação para os gêneros e as sexualidades (FURLAN; CARVALHO, 2020, p. 177).

Logo, para se manter no imaginário da população como um movimento de boas intenções de patrulha na escola, escondendo as reais intenções de controle curricular e a lógica econômica de suas proposições, o MESP percebeu que as disputas pelos saberes generificados e sexuados têm um grande apelo de massa no Brasil. Razão pela qual empreende uma defesa do combate a uma suposta "ideologia de gênero", sintagma construído pela Igreja Católica Romana e apropriado por outros grupos religiosos e conservadores como uma categoria política reacionária (JUNQUEIRA, 2017) ${ }^{6}$.

\section{A disseminação do combate à "ideologia de gênero": relações com o MESP e a porta de entrada da disseminação de preconceitos}

Em 2014, quando o MESP ganhou força no Brasil, também ocorreu a votação do Plano Nacional de Educação (Decênio 2014-2024), um documento balizador das metas a serem cumpridas pelos governos na melhoria da educação básica do país, das distribuições orçamentárias advindas do Fundo Nacional da Educação Básica (FUNDEB), do incentivo ao magistério e das estratégias a serem alcançadas visando o acesso à escolarização de todas/os as crianças e jovens em fase de escolarização. Tal documento está de acordo com as estratégias traçadas na Declaração Mundial sobre a Educação para Todos, redigida na Conferência Jomtien realizada pelo Fundo das

${ }^{6}$ No contexto religioso, o sintagma "ideologia de gênero" pode ser situado a partir das posições das igrejas em relação às pautas de direitos da ONU. Ele foi disseminado ainda no papado de João Paulo II e nos catecismos de Bento XVI através da movimentação de grupos católicos transnacionais como o "Manifs pour tous", a "Opus Dei" e por meio de conferências cristãs na Europa, América, África e Ásia que visam combater o feminismo e os direitos LGBT ao casamento religioso (JUNQUEIRA, 2017; FURLAN; CARVALHO, 2020). Então, é equivocado dizer que essa ideia pertence apenas a grupos religiosos conservadores neopentecostais no Brasil. Aliados à defesa da vida, a perseguição dos direitos sexuais e reprodutivos e ao combate da regulamentação do aborto, tanto a Igreja Católica quanto certas facções evangélicas, alinham-se à conjuntura da "ideologia de gênero" para criar estratégias de convencimento da população e evitar o debate dessas questões em locais significativos e formadores de opinião como escolas e universidades.

Revista Diversidade e Educação, v. 9, n. Especial, p. 509-531, 2021. 8853

Doi: $10.14295 /$ de.v9iEspecial.12588 $\quad$ E-ISSN: 2358- 
Nações Unidas para a Infância (UNICEF) e pela Organização das Nações Unidas (ONU), da qual o Brasil é um país signatário. Constam dessa aliança o atendimento às necessidades básicas da aprendizagem, a alfabetização na língua, a alfabetização científica e tecnológica, as políticas de igualdade e equidade e a valoração da diversidade étnica, cultural, sexual e de gênero.

A votação dos planos aconteceu em meio a um cenário de embate político e econômico favorecedor das coalisões do Governo Federal e do Congresso com a representatividade legislativa "boi-bala-bíblia", sob as influências das reivindicações dos movimentos de rua em 2013 e com a aguerrida manifestação do MESP em redes sociais. Antecedendo as votações dos Planos, essas conjunturas foram potencializadoras do avanço da discursividade de recusa partidária na organização das instâncias sociais, mas, também, de acordo com Silva et al (2014), congregadoras dos ideários de extremadireita atrelados às convicções segregadoras, autoritárias e mercadológicas (SILVA et al, 2014).

De acordo com Carvalho, Polizel e Maio (2016), dentro da Câmara e do Senado Federal e junto aos fóruns nacionais, estaduais e municipais de educação foram exercidas pressões contrárias à inserção dos termos gênero e diversidade nos referidos Planos de Educação votados a partir de 2014. Essa pressão teve forte respaldo de grupos empresariais ligados a sistemas de ensino particulares, como também um conclame à tradição judaico-cristã, ao binarismo do sistema sexo-gênero (homem-mulher; machofêmea; azul-rosa estão entre as expressões atreladas à imposição do modelo biológico do sexo-gênero), e ao bordão "Deus, Família e Propriedade" visando a moralidade no país e o extermínio de ideários comunistas nas escolas. Após longos debates e sessões de votação conduzidas por debates ideológicos e econômicos, a aprovação do Plano Nacional de Educação ficou condicionada à retirada de conceitos e terminologias supostamente difundidas pela "ideologia de gênero".

Segundo Carvalho et al (2015, p. 102),

os setores conservadores alegaram que o termo gênero, tomado por seu aspecto de construção social, geraria uma confusão na promoção da igualdade e da equidade entre as pessoas, e poderia, entre outras coisas, destruir a família, os valores tradicionais, as leis naturais, biológicas e religiosas para homens e mulheres ao favorecer políticas de promoção LGBT, de compreensão sobre a diversidade sexual, sobre os papéis de gênero, a despatologização da transexualidade, a discussão entorno da criminalização da homofobia. 
Além disso, há um apagamento semântico sobre o papel da mulher na construção da sociedade, sobre as discriminações de gênero, sobre o feminicídio, o assédio sexual e outros tipos de violência, desrespeitos e injustiças que poderiam ser pautados como metas governamentais e como conteúdos curriculares nas escolas.

Ainda em 2014, o Fórum Nacional de Educação (FNE), organizador da Conferência Nacional de Educação (CONAE) e do documento final da CONAE 2014, retomou as discussões acerca do respeito, da igualdade e da identidade de gênero e de orientação sexual (FÓRUM NACIONAL DE EDUCAÇÃO, 2014), mantendo, algumas questões e determinações suprimidas na aprovação da Lei no 13.005/2014 (BRASIL, 2014). Esse fato sofreu a perseguição do MESP na figura do deputado Izalci Lucas, responsável por cobrar informações do MEC e do FNE sob o pretexto desses órgãos estarem incorrendo na doutrinação de valores não relacionados à família de bem (BRASIL, 2015b). Conforme elucidou Lucas, as/os conservadoras/es dos valores tradicionais e o MESP estão empenhados em dizer

\begin{abstract}
que o conceito de 'Gênero' está sendo utilizado para promover uma revolução cultural sexual de orientação neomarxista com o objetivo de extinguir da textura social a instituição familiar. [...] Chegar-se-á a uma completa igualdade onde não haverá mais possibilidade de opressão de Gênero, mas também onde não haverá mais famílias, tanto as heterossexuais como demais famílias alternativas. [...] Em um mundo de genuína igualdade, segundo esta concepção, todos teriam que ser educados como bissexuais e a masculinidade e a feminilidade deixariam de ser naturais (BRASIL, 2015b, p. 17).
\end{abstract}

A ideia em destaque na citação acima, a nosso ver, é uma teoria conspiracionista sem nenhum sentido histórico, que fere o uso da categoria gênero como uma ferramenta de análise das disparidades sociais ou das estratégias de superação das desigualdades. Fere também a longa caminhada de consolidação do feminismo como movimento de reivindicação dos direitos das mulheres e das minorias sexuais. Além disso, endossa o paradigma cisheteonormativo da organização familiar e dos arranjos afetivos. Trata-se, portanto, de um acinte à discussão de gênero, sexualidade e diversidade sexual nas escolas, o que representa um retrocesso para a atualidade e para a luta LGBT, fazendose mais do que necessário que essas temáticas estejam presentes nos currículos e ambientes escolares para o combate de todas as vias de preconceito e discriminação.

A postura do MESP na votação dos Planos de Educação continua sendo disseminada em suas redes sociais através de falácias, argumentos generalistas e distorcidos dos contextos de discussão, posições particulares, vínculos com o 
pensamento religioso e dogmático das igrejas e de certos setores conservadores, posicionando as famílias como vítimas dos ataques feministas, comunistas e partidários de professoras/es e militantes.

Conforme se destacam nas figuras a seguir (Figura 2 e 3), o gênero passou a ser o carrossel do MESP, sendo acionado recorrentemente por meio de depoimentos feitos por estudantes, pais, mães e educadoras/es no site do movimento, cujo intuito é a denúncia de docentes e dos conteúdos que versam sobre o corpo, a genitalidade, os desejos afetivo-sexuais, a militância feminista, a militância LGBT, as performances e os papéis de gênero construídos culturalmente, as dissidências sexuais, a transgeneriedade e a transsexualidade, a LGBTfobia, o socialismo, o comunismo, as resistências históricas dos grupos sociais minoritários, entre outros assuntos dispersos em postagens maldosas e tendenciosas com o propósito de manipulação e pânico moral da população.

Figura 2: Denúncia de aluno sobre a proposta de uma redação com a temática gênero.

\section{ESCOLA SEM PARTIDO}

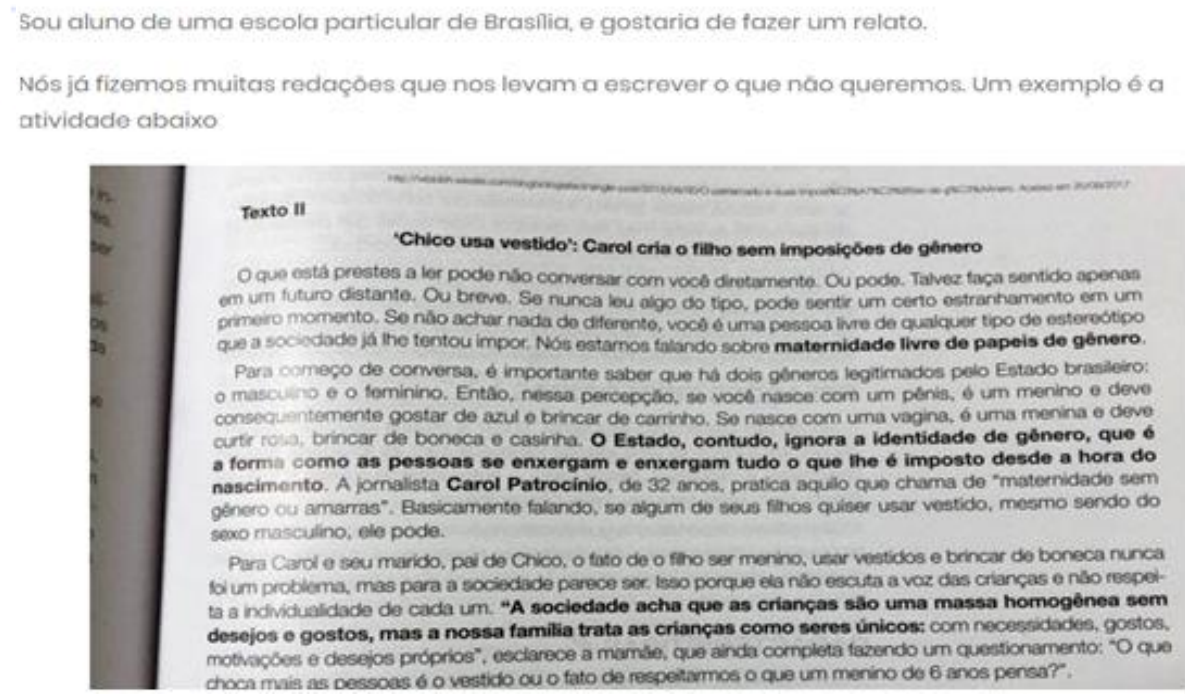

Fonte: http://escolasempartido.org 
Figura 3: Denúncia sobre experimentos psicológicos de gênero em aulas de Educação Física.

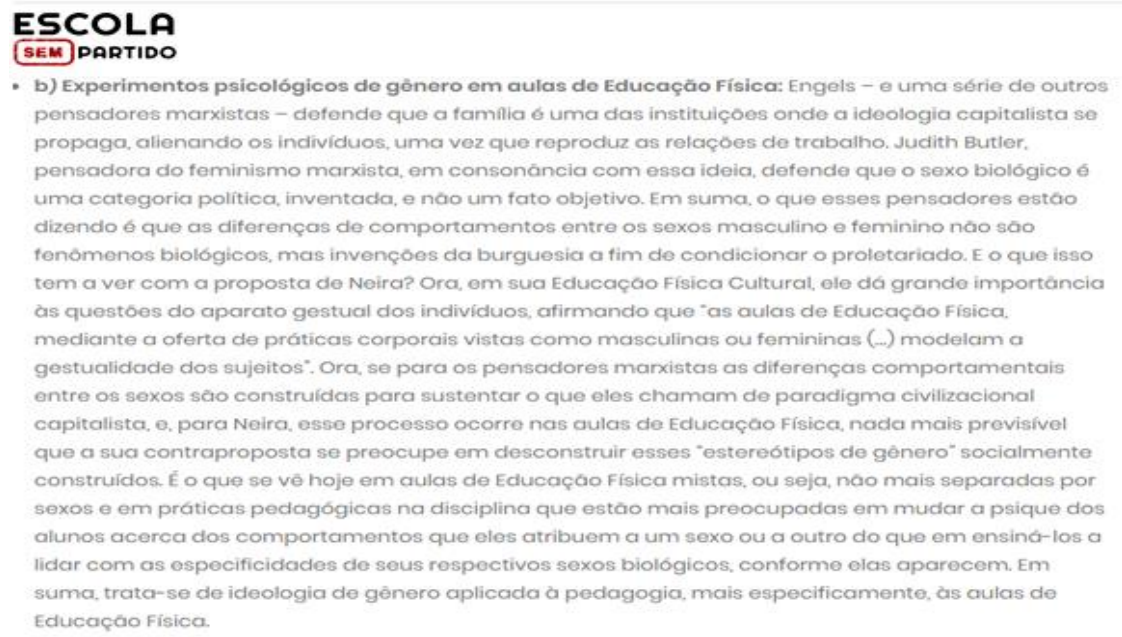

Fonte: http://escolasempartido.org

Essas estratégias visam, portanto, consolidar a posição do MESP e de sua visão de escola, política, sociedade, gênero, sexualidade, igualdade, desigualdade, minorias, religião, etc. Ele tem

definições específicas a respeito do que é ensino, aprendizado, como deve-se estruturar as relações entre professores e estudantes em sala e o trabalho com conteúdos curriculares. Isso leva a uma disputa pelo próprio sentido dessas palavras, constantemente recontextualizadas pelo movimento dentro de um léxico conservador. É a partir daí que o MESP delineia sua territorialidade dentro dos debates em que está inserido. Quando o movimento reivindica para si mesmo o direito de dizer quais são os 'verdadeiros' significados de ensinar, aprender, ser um professor, ser um estudante, ele está se colocando como o único interlocutor possível para o debate. [...] A forma que essa estratégia assume é uma de aspectos conservadores. É partindo desse viés que a concepção pedagógica do movimento é semeada (PENNA; SALLES, 2017, p. 20).

A estratégia da semeadura do MESP não parou no Plano de Educação. A BNCC sofreu influências dessas proposições na medida em que os setores empresarias, reliogiosas/os e conservadores acrescentaram suas convicções e crenças no documento norteador dos currículos da escola básica, pois instituir os currículos é instituir

[...] um dos locais privilegiados onde se entrecruzam saber e poder, representação e domínio, discurso e regulação. É também no currículo que se condensam relações de poder que são cruciais para o processo de formação de subjetividades sociais. Em suma, currículo, poder e identidades sociais estão mutuamente implicados. O currículo corporifica relações sociais (SILVA, 1996, p. 23). 
As relações sociais podem sustentar as narrativas de violência, segregação e preconceitos já enraizados desde o imaginário colonial brasileiro e defendidas pelas/os adeptas/os do MESP, como também entronizar uma verdade única, a perspectiva da história única com as anulações das lutas e conhecimentos vividos por grupos que não pertencem à ordem hegemônica.

Logo, temas como diversidade étnica e cultural, religião, LGBTfobia, racismo, e outros que precisam da incorporação curricular e da discussão social acabam sendo suprimidos dos documentos educacionais e das escolas, numa relação que sustenta as estruturas sociais hegemônicas, o machismo, o patriarcado, a heterossexualidade compulsória, a conjugabilidade da família tradicional e a invisibilidade de mulheres, de gays, de lésbicas, de bissexuais, de pessoas transgêneras e daquelas/es que não se enquadram na normatividade e representam uma dissidência de comportamentos cristalizados.

\section{O MESP e os possíveis impactos da supressão das discussões de gênero e diversidade sexual na BNCC para o ensino de Ciências e biologia}

Em sua crítica ao desmanche da educação pública e da BNCC, Marta Bellini (2020) recobra atenção para as peças que as modernas corporações empresariais ${ }^{7}$ pregam novamente no país, imbuídas de controlar os currículos e de colocar dogmas e o ensino religioso no lugar da filosofia, da história, do ensino de ciências e biologia ao preconizar o conceito de família (a tradicional ou nuclear estruturada por pai - mãe filho exclusivamente) que nunca foi a realidade social e cultural brasileira. Tampouco a coincidência cisgênera do sexo atribuído ao nascimento com as identidades de gênero construídas ao longo da vida pessoal e social. Nesse propósito, não é novidade o vínculo de interesses partidários com empresárias/os e religiosas/os na perspectiva de uma educação moral e na colonização das chamadas competências e habilidades programadas para a vida social. Para a autora,

não há dúvida de que a BNCC atendeu às forças políticas da elite empresarial do Brasil, sobretudo aquelas voltadas ao nicho da educação. Quem diria que empresários da cervejaria, de cosméticos, imobiliaristas, iriam produzir educação? Não, não produzirão ensino ou educação. Apenas encontraram,

7 A saber: Fundação Lemann, Fundação Bradesco, Grupo Natura, Fundação Ayrton Senna, Grupo Editorial Abril, Movimento Todos pela Educação, Movimento Amigos da Escola, Grupo Cogna-Kroton Editorial, Fundação Roberto Marinho, Itaú Cultural, Movimento Brasil Livre, Instituto Millenium, Instituto Liberal, para ficar naqueles que tiveram maior poder intervencionista na proposição da BNCC. 
nos EUA, um modelo de captura aparentemente legal de recursos do ministério mais polpudo do governo federal e a aplicaram no Brasil. Não é de educação que a BNCC trata. A BNCC votada por representantes de setores produtivos ou financeiros foi um mecanismo de infiltração e desestruturação do Ministério da Educação por esses segmentos do mercado (BELLINI, 2020, p. 27).

A BNCC também apresenta a influencia de segmentos religiosos e de movimentos conservadores, entre os quais o próprio MESP defendido por Miguel Nagib, Olavo de Carvalho, Bia Kicis, Izalci Lucas, por Bolsonaro e correligionárias/os.

Como documento norteador das proposições de ensino, qualquer narrativa ou desenho educacional presente na BNCC incide nas correlações sociais e formativas da escola. Logo, ao contestar a competência do MEC e do CNE para a elaboração dos Planos de Educação e, em seguida, para a elaboração da BNCC, apartando as/os educadoras/es da discussão e da confecção do documento, o MESP fez a afirmação de que os direitos da aprendizagem conflitam com os direitos da família, ampliando efetivamente a interferência privada na escola. Por outro lado, conforme explicita Elizabeth Macedo (2017), as demandas conservadoras do MESP em relação ao conteúdo da BNCC apontam diretamente para o que deve ser excluído da educação a fim de atender aos interesses familiares, morais e religiosos.

\begin{abstract}
As exclusões citadas explicitamente se referem a demandas políticopartidárias, raciais, de gênero e de sexualidade. O potencial dessas exclusões para deslocar as articulações sobre a BNCC é preocupante, na medida em que elas focam diretamente demandas de grupos minoritários - de raça, gênero e sexualidade - que, ainda timidamente, têm conquistado algum espaço. $\mathrm{O}$ próprio jogo político que levou a uma BNCC em que uma listagem de objetivos é entendida como necessária para que direitos de aprendizagem e ensino se materializem já embute uma série de exclusões, ainda que não admitidas explicitamente (MACEDO, 2017, p. 517).
\end{abstract}

Por esses aspectos, podemos dizer que o amparo aos direitos humanos, à educação para as sexualidades e para os gêneros na BNCC é pífio, fragmentado e descompromissado com a formação íntegra da cidadania. A última versão, promulgada em 2019, venceu a posição das notas do CNE em relação à importância dos debates de gênero e sexualidade, desintegrando em seu texto temas relacionados a gênero, orientação sexual e diversidade sexual. Numa busca textual básica pelo documento usando as ferramentas de edição, a palavra gênero é mencionada apenas para se referir aos gêneros textuais discursivos; a palavra sexualidade é citada 5 vezes no âmbito explicativo e na disposição das competências e habilidades, sem contextualizações e 
encaminhamentos; e os termos "diversidade sexual" e "orientação sexual" não aparecem no documento.

Considerando essas questões quando analisamos o itinerário formativo de "Ciências da Natureza e suas Tecnologias" da BNCC e nas discussões delegadas às disciplinas de ciências e biologia, consideradas, muitas vezes, os territórios nos quais se alocam as discussões de sexualidade, corpo e gênero, o apagamento torna-se mais acentuado quanto pensamos as práticas pedagógicas, os encaminhamentos transversais e as pautas sociais importantes a serem ensinadas e debatidas no ensino fundamental e médio.

Esse foi um caminho de restrições imposto quando comparamos as primeiras versões da BNCC que vieram a público ainda no Governo Dilma Rousseff e quando o CNE e o MEC detinham mais autonomia para os seus encaminhamentos curriculares. De acordo com Elder Luan da Silva (2020), houve um favorecimento das questões de gênero, sexualidade, diversidade e diferença nas primeiras versões anteriores da BNCC. Para efeitos de comparação, na segunda versão são "26 as menções específicas à sexualidade, e 38 a gênero [...], um crescimento de menções a relações de Gênero, orientação Sexual, e homofobia, e o aparecimento de expressões como "questões de gênero, corpo e sexualidade" (SILVA, 2020, p. 148).

Quando se observam as proposições do Ensino Fundamental, a versão final aloca as discussões de sexualidade na unidade temática "Vida e Evolução", prevista para o $8^{\circ}$ ano e restrita à abordagem de questões reprodutivas e hormonais, das Infecções Sexualmente Transmissíveis (ISTs) e da prevenção da gravidez na adolescência (BRASIL, 2018). Já para o Ensino Médio, a unidade temática "Vida, Terra e Cosmos" menciona os desafios enfrentados pelas/os jovens na evolução humana e no combate ao preconceito e à discriminação sem menção ao gênero, à sexualidade e à diversidade sexual.

Tais restrições recrudescem uma visão fisiologista, higienista e normativa das relações humanas e dos papéis e performances de gênero vivenciadas na sociedade. Ancoradas em determinismos biológicos (CARVALHO, 2020), que são fortemente recobrados em discursos religiosos, nas biopolíticas sociais, nas tentativas de padronização dos corpos, dos gêneros e das sexualidades. Por outro ângulo, tais restrições podem ser tomadas como violências sociais (DINIS, 2011). Ao se omitir as discussões plurais para o entendimento da vida humana, a BNCC comete uma prática de 
violência implícita, simbólica e epistemológica. "Essa grande operação de silêncio, de roubo de fala, que se sintetiza na busca da 'harmonia social', é bem o signo da anulação política" (OLIVEIRA, 1999, p. 61) e também da modulação que importa em classificar, controlar e corrigir os saberes, os desejos, as vontades, os aprendizados, os corpos, a vida cultural e biológica em sua multiplicidade.

Nesse contexto, a BNCC não deixa de reiterar a heteronormatividade em generalizações da mesma maneira que o fazem a mídia, as igrejas e as escolas com posturas conservadoras.

A supressão das questões de gênero e sexualidade evidenciam o lado cruel da reforma educacional e das frentes contrárias ao pluralismo de ideias, à livre expressão e ao pensamento crítico, em especial, a frente suprapartidária do MESP. Permanecem as questões burocráticas e a normatividade, principalmente, quando as demandas são subsidiadas por doutrinações institucionalizadas via currículo, com o apoio da burocracia do MEC, dos meios de comunicação, dos setores religiosos e movimentos conservadores que enfatizam a transferência do espaço privado para dentro das escolas, o tecnicismo e o conteúdismo das informações, a extinção da diversidade cultural e sexual nas instituições de ensino, as práticas persecutórias direcionadas aos gêneros e às sexualidades, a coibição da liberdade de expressão e da emancipação como projeto de vida, enfim, trata-se da cidadania negada (GOHN, 2002; MACEDO, 2017; CARVALHO, 2020).

\section{Considerações Finais}

É perceptível que o MESP carrega consigo uma postura conservadora, reacionária e de viés moral. Seu endosso à uma suposta "ideologia de gênero" pode ser compreendido menos por uma tendência religiosa por si, mas, sim, pela tentativa de refrear as políticas públicas educacionais e a pluralidade de ideias nas escolas.

Travestido de baluarte da neutralidade política e do apartidarismo, as/os simpatizantes do MESP ocupam cadeiras nas bancadas "boi-bala-bíblia" e se coligam a diversos partidos políticos com interesses educacionais muito específicos.

O MESP se consolidou como um movimento fundamentalista de direita e extrema direita que apregoa uma pedagogia do medo, da vigília e do pânico moral em relação à subversão da ordem estabelecida. Por outro lado, representa interesses corporativos e empresárias voltados ao controle da escola, à indeterminação do pensamento crítico e à monetarização da educação. Tais alinhamentos não estejam 
evidentes à grande maioria da população, o MESP uso de convencimento ao cercear a liberdade de cátedra, a docência e os conteúdos eleitos como currículos.

Em sua visão retrógada e contrária aos avanços teóricos, aos estudos e às causas militantes e LGBT, questões como gênero, sexualidade e diversidade sexual não podem ser pautadas como temas importantes para a transformação da sociedade, para a igualdade, a equidade e a visibilidade das reinvindicações dos grupos sociais minoritários.

O MESP defende que princípios morais, econômicos, religiosos e políticos devem ficar à cargo da orientação de familiares, que a escola deve se restringir a conteúdos básicos e se esmiuçar da participação política e da formação crítica das/os estudantes. No contexto conturbado e de polarização das lutas sociais vivido no Brasil desde 2013/2014, essa estratégia de engessar a educação é extremamente perigosa e pode consubstanciar fascismos, relações sociais excludentes e segregações no acesso à educação básica.

A nosso ver, a escola deve, sobretudo, ser um espaço de debates, de combate a qualquer forma de preconceito, violência e discriminação; deve ser também um espaço de reavivamento histórico onde se discute e se problematiza as bases autoritárias da sociedade brasileira a fim de quebrar as proposições hegemônicas e opressivas. Entretanto, tal postura da escola tem sido indeterminada com a reforma educacional, com a diminuição de investimentos públicos na qualidade da formação ds/dos estudantes e com as perspectivas privatistas que tentam operar as intuições de ensino como bolsa de valores.

O que tencionamos apresentar em nossa discussão, comparando as questões políticas, a emergência do MESP e a produção da BNCC, foi uma crítica ao apagamento gradual de termos e atuações que fazem referência ao gênero, à sexualidade e à diversidade sexual.

Em relação ao ensino de Ciências e Biologia, considerados pelas tradições escolares o território de discussão da sexualidade humana, das diferenças e performances de gênero, das vivências do corpo biológico e social, a BNCC por via de seu itinerário "Ciências da Natureza e suas Tecnologias" retrocede às posturas políticas e curriculares de 50 anos atrás, que não consideravam o desenvolvimento cognitivo, a alfabetização científica e a multiplicidade de identificações das/os estudantes, e focavam em uma visão médica, bem comportada e padrão das vivências afetivas 
humanas. Além disso, a Base despreza o combate aos fundamentalismos e posturas opressivas na sociedade, promovendo, a desigualdade social nos alicerces educacionais do país. Portanto, preocupa-nos também o fato de a BNCC servir à finalidade de padronização curricular, de orientação para a elaboração de roteiros e de livros didáticos conteudistas destinados a realidades sociais diferentes no país e como indutora das perspectivas formativas nas licenciaturas.

Como o currículo acontece pelo que se é narrado e também por aquilo que dele se omite, dele se escapa e com ele se confabula, apostamos no poder de resistência das frentes progressistas, das militâncias feministas e LGBT, dos estudos de gênero, das redes sociais, da mobilização dos grupos minoritários como paredista diante do MESP e frente às correntes contrárias à sociedade plural. Decorre dessa resistência, a saber, o posicionamento do Supremo Tribunal Federal (STF), que soterrou juridicamente as tentativas legislativas anti-gênero do MESP ao julgar em junho de 2020 a inconstitucionalidade de PL's do movimento apresentados nos municípios de Nova Gama (GO), Foz do Iguaçu (PR), Cascavel (PR), Ipatinga (PR) e PL's do Estado de Alagoas com o veredicto de que a censura às temáticas de gênero, sexualidade e diversidade sexual nas escolas viola a ação constitucional do Estado, os princípios da laicidade, a pluralidade de ideias e concepções pedagógicas, a liberdade de cátedra, o direito de crianças e adolescentes quanto à prevenção de violências sexuais, de gênero e preconceitos e o combate a todo tipo de discriminação (BRASIL, 2020).

Em termos práticos, isso significa jurisprudência para que os tribunais de justiça se fundamentem nessa decisão e embarguem os PL's que incentivam a perseguição, a censura e o cerceamento dos conteúdos e abordagens escolares sobre gênero e sexualidade. Significa, também, que as/os docentes não poderão ser culpabilizadas/os pela discussão dos temas e podem, certamente, desenvolverem suas atividades ainda que o currículo padronizado da BNCC não pressuponha e oriente quanto a importância dos mesmos para a vida em sociedade.

Novas atividades de censura podem surgir desse contexto de união entre interesses econômicos e os interesses conservadores religiosos. Eles irão insistir no domínio curricular. Nós, educadoras/es, iremos resistir! Não, não é balbúrdia... É direito! 


\section{Referências}

BELLINI, Marta. O desmanche da educação pública nos governos Temer e Bolsonaro: o caso da Base Nacional Comum Curricular e o ensino de ciências. Koan Revista de Educação e Complexidade, Cianorte, n. 8, p. 05-30, 2020.

BIROLI, Flávia. Uma mulher foi deposta: sexismo, misoginia e violência política. IN: RUBIM, Linda.; ARGOLO, Fernanda. (orgs.) O golpe na perspectiva de gênero. Salvador: Edufba, 2018.

BRASIL. Lei 9.394 de 20 de dezembro de 1996. Estabelece diretrizes e bases da educação nacional. Disponível em: <https://www.planalto.gov.br/ ccivil_03/Leis/L9394.htm>. Acesso em: 16 jan. 2021.

Presidência da República. Casa Civil. Lei no 13.005, de 25 de junho de 2014. Aprova o Plano Nacional de Educação - PNE e dá outras providências. Brasília, DF, 25 jun. 2014. Disponível em: http://www.planalto.gov.br/ccivil_03/_ato20112014/2014/lei/113005.htm. Acesso em: 16 jan. 2021.

Câmara dos Deputados. Projeto de Lei no 867, de 23 de março de 2015. Inclui, entre as diretrizes e bases da educação nacional, o Programa Escola sem Partido. Brasília, DF, 2015a. Disponível em: <https://www.camara.leg.br/proposicoesWeb/ fichadetramitacao?idProposicao=1050668>. Acesso em: 16 jan. 2021.

Câmara dos Deputados. Requerimento de Informação nº 565, de 2015.

Requer ao Ministro de Estado da Educação informações sobre o Documento Final do Conae-2014, assinado e apresentado pelo Fórum Nacional de Educação como passo na articulação da educação nacional como política de Estado, no qual define, contrariamente ao que foi estabelecido durante a votação do PNE nesta casa, a ideologia de gênero como diretriz obrigatória para o PNE, o planejamento e as políticas educacionais no Brasil. Brasília, DF, 2015b. Disponível em: <https://www. camara.leg.br/proposicoesWeb/prop_mostrarintegra?codteor $=1337320 \&$ filename $=$ RIC + 565/2015>. Acesso em: 16 jan. 2021.

Presidência da República. Lei no 13.415, de 16 de fevereiro de 2017.

Estabelece as diretrizes e bases da educação nacional. Brasília, DF, 16 fev. 2016.

Disponível em: <http://www.planalto.gov.br/ccivil_03/_ato2015-

2018/2017/lei/113415.htm>. Acesso em: 16 jan. 2021.

. Ministério da Educação. Base Nacional Comum Curricular. 2018. Disponível em: <http://basenacionalcomum.mec.gov.br/images/BNCC_EI_EF_110518_versaofinal_site pdf>. Acesso em: 16 jan. 2021.

Câmara dos Deputados. Projeto de Lei no 246, de 04 de fevereiro de 2019. Institui o Programa Escola sem Partido. Brasília, DF, 2019. Disponível em: $<$ https://www.camara.leg.br/proposicoesWeb/fichadetramitacao?idProposicao=2190752 >. Acesso em: 11 abr. 2019. 
Supremo Tribunal Federal. Diversidade: jurisprudência do STF e bibliografia temática. Brasília, DF: STF / Secretaria de Documentação, 2020. Disponível em: <http://www.stf.jus.br/arquivo/cms/noticiaNoticiaStf/anexo/ColetDiversidade.pdf>. Acesso em: 15 jan. 2020.

CARA, Daniel. O Programa "Escola Sem Partido" quer uma escola sem educação. In: SOUZA, A L. S et al. A ideologia do movimento escola sem partido: 20 autores desmontam o discurso. São Paulo: Ação Educativa, 2016. p. 23-48.

CARVALHO, Fabiana Aparecida de. Quando a exceção se torna regra totalitária: o cruzamento do movimento escola sem partido com a persecução aos estudos de gênero e à educação para as sexualidades. Revista Educação e Linguagens, Paranavaí, v. 9, n. 17, p. 154-179, 2020.

CARVALHO, Fabiana Aparecida de et al. Políticas públicas e (in)visibilidades escolares: entre (des)conhecer, apagar e trabalhar com o combate à violência de gênero. In: CORREA, Crishna Mirella A.; MAIO, Eliane Rose. (orgs.). Observatório e violência de gênero - entre políticas públicas e práticas pedagógicas. Curitiba: CRV, 2015. p. 99-116.

CARVALHO, Fabiana Aparecida de; POLIZEL, Alexandre Luiz; MAIO, Eliane Rose. Uma escola sem partido: discursividade, currículos e movimentos sociais. Semina: Ciências Sociais e Humanas, Londrina, PR, v. 37, n. 2, p. 193- 210, 2016.

DINIS, Nilson Fernandes. Homofobia e educação: quando a omissão também é signo de violência. Educar em revista, v. 27, n. 39, p. 39-50, 2011.

ESCOLA.... 2021. Disponível em: <http://www. escolasempartido.org>. Acesso em: 16 jan. 2021.

ESPINOSA, Betty. R. Solano.; QUEIROZ, Felipe. B. Campanuci. Breve análise sobre as redes do Escola sem Partido. In: FRIGOTTO, Gaudêncio. (Org.). Escola "sem" partido: esfinge que ameaça a educação e a sociedade brasileira. Rio de Janeiro: UERJ/LPP, 2017. p. 49-62.

FÓRUM NACIONAL DE EDUCAÇÃO (FNE). Documento Final CONAE-2014. 2014. Disponível em: http://fne.mec.gov.br/images/doc/DocumentoFina240415.pdf. Acesso em: 16 abr. 2021.

FOUCAULT, Michel. O nascimento da biopolítica. São Paulo: Martins Fontes, 2008.

FURLAN, Cássia Cristina.; CARVALHO, Fabiana Aparecida de. Comunismo e gênero no Escola sem Partido: notas para não sucumbir a uma pedagogia fascista. Revista Da FAEEBA - Educação E Contemporaneidade, v. 29, n. 58, 168-186, 2020.

GOHN, Maria da Glória. Educação, trabalho e lutas sociais. In. GENTILLI, Pedro.; FRIGOTTO, Gaudêncio. (Orgs.). A cidadania negada: políticas de exclusão na educação e no trabalho. São Paulo: Cortez; Buenos Aires, Argentina: CLACSO, 2002. 
JUNQUEIRA, Rogério Diniz. "Ideologia de gênero": a gênese de uma categoria política reacionária - ou: a promoção dos direitos humanos se tornou uma "ameaça à família natural"? In: RIBEIRO, Paula Regina Costa; MAGALHÃES, Joanalira. C. (orgs.). Debates contemporâneos sobre educação para a sexualidade. Rio Grande: Editora da Furg, 2017. p. 25-52.

KRASILCHIK, Myriam. Reformas e realidade: o caso do ensino das ciências. São Paulo em perspectiva, São Paulo, n. 14, p. 85-93, 2000.

MACEDO, Elizabeth. As demandas conservadoras do movimento escola sem partido e a Base Nacional Curricular Comum. Educ. Soc., Campinas, v. 38, n. 139, p.507-524, abr.-jun., 2017.

MIGUEL, Luis Felipe. Da "doutrinação marxista” à "ideologia de Gênero" - Escola sem Partido e as leis da mordaça no parlamento brasileiro. Direito \& Práxis, Rio de Janeiro, v. 7, n. 15, p. 590-621, 2016.

OLIVEIRA, Francisco Maria Cavalcante. Privatização do público, destituição da fala e anulação da política: o totalitarismo neoliberal. In: OLIVEIRA, Francisco.; PAOLI, Maria Célia Pinheiro M. (orgs.). Os sentidos da democracia: políticas do dissenso e hegemonia global. Petrópolis: Vozes, 1999.

PENNA; Fernando de Araújo; SALLES, Diogo da Costa. A dupla certidão de nascimento do Escola sem Partido: analisando as referências intelectuais de uma retórica reacionária. In: MUNIZ, Altemar da Costa; LEAL, Tito Barros (orgs.). Arquivos, documentos e ensino de história: desafios contemporâneos. Fortaleza: EdUECE, 2017. p. 13-38.

RUBIM, Linda.; ARGOLO, Fernanda. (orgs.) O golpe na perspectiva de gênero. Salvador: Edufba, 2018.

SACRISTÁN, Jimeno G. O que significa o currículo. In: SACRISTÁN, Jimeno G. (org.). Saberes e incertezas sobre o currículo. Porto Alegre, 2013, p. 16-35.

SILVA, Adriana Brito da et al. A extrema-direita na atualidade. Revista Serviço Social \& Sociedade, São Paulo, n. 119, p. 407-445, jul./set. 2014.

SILVA, Eder Luan dos Santos. Pânico moral e as questões de gênero e sexualidade na BNCC. História, histórias, v. 8, n. 16, p. 138-162, jul./dez. 2020.

Tomaz Tadeu da. Documentos de identidade - Uma Introdução às teorias do currículo. $3^{\text {a }}$. ed. Belo Horizonte: Autêntica, 2007.

Identidades terminais: as transformações na política da pedagogia e na pedagogia da política. Petrópolis: Vozes, 1996. 